\title{
Power Sharing in Malaysia: Beyond Unity and Political Duplicity
}

\author{
Kartini Aboo Talib @ Khalid $^{1}$, Nidzam Sulaiman ${ }^{1}$, Wan Kamal Mujani ${ }^{2}$, Siti Rogayah Tibek $^{2}$, Ermy Azziaty \\ Rozali $^{2} \&$ A. Rasyid $\mathrm{Ali}^{3}$ \\ ${ }^{1}$ Institute of Ethnic Studies, UKM, Malaysia \\ ${ }^{2}$ IKRAB, UKM, Malaysia \\ ${ }^{3}$ Faculty of Tarbiyah, Institut Agama Islam Negeri Sultan Thaha Saifuddin, Jambi, Indonesia \\ Correspondence: Kartini Aboo Talib @ Khalid, Institute of Ethnic Studies, UKM, Malaysia. E-mail: \\ kartinikhalid@gmail.com
}

Received: April 17, 2013 Accepted: June 13, 2013 Online Published: August 1, 2013

doi:10.5539/ass.v9n10p274 URL: http://dx.doi.org/10.5539/ass.v9n10p274

The research is funded by the Religion and Social Cohesion grant LRGS/BU/2011/UKM/CMN/04. Authors would like to thank Dr Karen Vautour in Salem, Massachusetts for her editing contribution.

\begin{abstract}
This article examines power sharing models and applies evidence from the Malaysian context. Most power sharing models display a high tolerance for diverse behaviors and use negotiation to restore balance when necessary. Moreover the workable power sharing model is one that improvises in order to meet competing plural contexts. Although the principal of equality is debatable, the tendency is to fulfill everyone's interests by stretching limited resources to avoid conflict. The Malaysian government has placed significant effort into national programs that cultivate and nurture unity in its unique multiethnic society. Nevertheless, criticism has always regarded intensive government efforts as political duplicity set on maintaining the status quo of a regime. Such propaganda limits the pluralistic nature of society and the ability of its citizens to enjoy basic rights. Thus factors for power sharing are varied and most are leaning toward securing interests and benefits with resource scarcity attached to them. This article applies a qualitative method with process tracing techniques to build its arguments and to delineate evidence. As a result, the findings promote a stance beyond political duplicity and provide an alternative understanding for viewing multiculturalism as an ethnic dimension rather than a distinct ethnic social relation.
\end{abstract}

Keywords: power sharing, coalition, moderation, multiethnic, social cohesion

\section{Introduction}

There is no pure race in this world. Variations within racial groups that include a range of genetics, mass migration, and mixed marriages really redefine a person's look and outlook. Furthermore what defines race depends on what a person sees, believes and hears. This semantic argument is true when assessing nation states and multiethnic societies (Kessler, 2012). Malaysia is a complex and diverse pluralistic society with layers of interaction in various contexts. Regardless of what definition fits to explain the races, the nation displays various cultural histories that involve free-flowing processes of migration, as well as cultural borrowing and adaptation. This complex multiethnic nation is being integrated wisely by a government that seeks to ensure that plurality and diversity are accepted in a delicately balanced relationship (Shamsul, 2011:35).

Building a multiethnic nation is a huge challenge. Pursuing and maintaining unity in diversity (Note 1) takes more than just a political will to achieve it. Malaysia has made tremendous efforts to realize such unity in diversity. Dating back to 1948, the Malay confederation was established to convince the British colonial government that Malaysia was ready for independence. Adhering to this requirement, the Communities Liaison Committee was formed in 1949-1951 to appoint a leader or representative of each race, informing each of the need for a political coalition as a prerequisite to independence (Fernando, 2012). Later, the political alliance was established in 1951 to show the seriousness of the nation to the idea of independent. Social cohesion was the key indicator that ensured the three major races (Malays, Chinese and Indians) were able to live together simultaneously, maintaining peace and harmony. 
Many discussions referring to this colonial requirement led to many more forms of coalition among races and particularly political parties. Readiness for independence was demonstrated and although such nascent unity was in question, it evolved into a strong alliance among political parties that represented each race. This formula of a grand coalition created a precedent for many more coalitions within a multiethnic society and organisations. Additionally, the coalition model is the preferred model in multi-racial societies because of its ability to promote opportunity to each competing group and to represent many interests; however efficiency or effectiveness of power sharing is debatable. First, the model is said to represent the interests of each race. Unfortunately due to resource scarcity the majority race is likely to dominate while the minority must accommodate. Secondly, the majority group will strengthen its status quo while the minority has to be creative in meeting its needs. Thirdly, the coalition model may inspire the few elite members at the top of each race to benefit from interactions and relations while others do not. Here effectiveness is varied and relatively questionable.

\section{Research Method}

The method applies in this article is mainly qualitative. Discussions and arguments are developed using the process tracing method to highlight the intervening variables that contribute fairly important to the social cohesion and unity in Malaysia. This process tracing offers possibility of identifying different causal paths that lead to a similar outcome. In addition, process tracing also allows evidences to be tested and retested against a theory and this would allow a researcher to refine a theory with new evidences (George \& Bennett, 2005). Process tracing also uses historical explanation of events developed over time that bring about the causal mechanism to explain a phenomenon. In this case, process tracing method is applied in looking at the historical explanation particularly the establishment of Communities Liaison Committee in 1949 including the formed of a political alliance in 1951 to show to the British that the major races in Malaya were ready for independence and election. The alliance party later changed its name into Barisan Nasional in 1973 and as the nation developed and progressed over time, the same grand coalition formula was used by other opposition parties such as Pakatan Rakyat in 2008.

Furnival's theory and assumption on plurality creates conflict is challenged in this article through factors including the power sharing model, government efforts and strong leadership, the application of moderation approach, and a shift of paradigm from communal sentiments to good governance championed by civil societies. These evidences simply contribute to validate the process tracing method particularly the collection of events that help to explain the social cohesion and unity contexts in Malaysia. Here, applying the historical explanation on events and their progress developed over time are useful tools for a researcher to stick to his or her evidences in challenging or refining a theory. Evidences gathered from the historical events, experiences, everyday observation, and official state recognitions of rituals and cultural celebrations are substantial to exhibit the present power sharing and ethnic relationships in Malaysia.

\section{The Power Sharing Models: Context for Improvising}

The idea of power sharing is necessary to create an avenue for competing groups to work together and perhaps to be able to avoid hostility. In fact, sharing limited resources works best in a plural context allowing each competing entity to acknowledge the need to work collectively. In this discussion on the power sharing models, most models are promoting coalition or alliance that encourages peaceful methods rather than provoking means. Applying a high tolerance, taking into account the majority and minority votes, and finding common ground as much as possible ensure a reciprocal understanding and acceptable decisions. Moreover, these models cannot work independently without improvising some conditions to the circumstances, either accommodating the current demands or eliminating the unnecessary ones. Ironically, both conditions trigger the very basic questions of what, why, how, and who would benefit from any decision. These conditions could also lead to misperceptions of power sharing models such as elite groups or the dominant majority faring better than non-elites and minorities.

Power sharing models can be viewed in several ways. Lijphart $(1969,1977,1991)$ argues that in competing groups with multiple interests, the consociation model is inevitable. Consociation consists of four basic principles including grand coalition, mutual veto, segmental autonomy, and proportionality. Grand coalition is a joint co-operation among competing groups to form an alliance. The coalition provides each competing group an opportunity to voice its opinion and interests and to be able to find a common understanding or interests that best benefit the coalition. In order to maintain a harmonious relationship among all groups, each may have to practice a high degree of tolerance for any emerging issues. A form of coalition does not require a group to abandon its values and interests, or to change its objectives to fit in a coalition, but the group must be flexible or open to accepting suggestions from the other members. Furthermore, a group must be willing to tailor its interests and 
objectives to best promote the needs of all parties without subordinating any group members, particularly those in the minority.

Secondly, mutual veto refers to each group in the coalition having the right to accept or reject a decision made by the majority, provided that those decisions do not jeopardise the group's wellbeing. Thirdly, segmental autonomy provides a platform for each group to exercise its autonomy on matters pertaining to its own affairs including education, ritual and belief, and moral values. Such autonomy is legally based and must adhere to the law of the land. Ensuring group survival and sustainability, this provision helps the group prepare its next generation with social constructive ideas and agendas. Fourth, proportionality involves the distribution of resources to all, including welfare benefits, entitlements and public services. Distribution of limited resources is not based on the principle of equality but on a case by case basis or need. The principle of equality is debatable in that to give an equal amount of resources to communities with different layers of poverty or wealth is morally wrong. In a plural society, distribution of resources can trigger a conflict and managing resource scarcity among competing interests can be tricky.

Another model to consider when discussing multiple competing groups is the coalition bargaining model. This model is a dynamic bargaining model applied to coalition formation. Diermeier et al. (2008:485) argues that equilibrium could be maintained in this coalition formation through negotiation. The negotiation allows members to voice their proposals. If negotiation fails, there are chances for coalition members to extract favourable agreement from their counterparts or the process continues. This majority bargaining process also means that it is not necessary to reach consensus among all negotiating parties to come to an agreement. However the fear of being excluded from coalition formation would create a disadvantaged position, especially when the other groups manage to support each other and conspire to reject the uncooperative group. Furthermore, Eraslan and Merlo (2002) argue that the fear of being excluded from future proposals and processes of coalition formation leads to an ineffective decision. Such fear would predispose parties in the coalition to make a quick decision on a certain matters in order to avoid an inefficient result.

Holyoke (2009:360) argues that competition among interest groups can turn into a collective form of coalition if pressure from the legislators and competitor groups is high. Furthermore he argues that competition among interest groups can become more competitive when a potential policy outcome is perceived to bring harm to members of interest groups. Thus interest groups may need to reconsider their objectives and find the best way to achieve their goals, even to the extent of working together with their competitors. Consequently, this lobbying mechanism significantly targets legislators. When competing interest groups recognise their power limitations and resource scarcity, rather than fight with their competitors over resource drain, they may be willing to pool their strengths and agree to form a coalition that advocates for their cause.

Coalition in a majority system offers ways to win voters' votes. Bargsted and Kedar (2009) note that in a majority system, voters' preferences are subjective but they are likely to incorporate chances for victory when choosing a candidate or political party, either individually or as part of a coalition, before casting their ballots. Strategically voters are likely to support a candidate from a coalition party that provides a strong national-unity ideology. Different political parties that form a coalition demonstrate positive credibility when they can overcome competing differences and interests and are able to convince voters that common national agendas are able to be established for those well being of all citizens. Another facet of party behaviour is that parties do not represent their voters' perspectives directly, but they are likely to adopt relative extremism or relative moderation in order to maximise votes in an election or to influence coalition outcomes (Warwick, 2009). Furthermore, Kedar's reasoning model anticipates that the moderate or extreme positions will involve compromise across party positions. In a left or the right wing party, members will eventually move their position of decision making or agenda manoeuvring closer to their polar preference (Warwick, 2009: 277). Here bargaining is at play and having a coalition-based system may create cross-pressures for serving party supporters. On one hand, political parties have electoral clienteles that expect to see their ideological stances reflected the party's political pursuit. On the other hand, party supporters would like to see those stances be translated into a policy that promises to benefit them.

Stevenson, et. al (1985) discuss a concept of coalition that is diverse and applies to different contexts. The management context focuses coalition within an organisation that is composed of employees, managers, and stockholders over issues including conflict over budget, allocation of functions and precedent. Additional bargaining issues are decision making processes, problem solving mechanisms, goal setting competitions, and allocating scarce resources. The aggregate of problems varies depending on a crisis or a non-crisis condition. The leverage for bargaining is higher in a non-crisis than a crisis condition because the latter would restrict each group to bargain over each preference when resources are limited and crisis resolution is at stake. Stevenson 
(1985) and Mintzberg (1983:259) argue that a political analysis model of coalition is translated into organisational policy and action within the framework of legislative coalition in order to maximise policy outcome for members. Thus a coalition is formed to maximise this advantage because people or parties are self-interested. If they support similar ideologies, forming a coalition would enhance their chances of winning on proposals, decisions, or votes

In addition to power sharing models advocated by most Western scholars, the Islamic model for coalition applies the Wasatiyyah (Note 2) approach that is a moderation model of action. This model promotes both dissenting and concurring opinions that apply moderation where the intensity to agree or disagree is expressed in a temperate way or with non-excessive action. Matters are handled by finding a solution that is right and appropriate. The moderation approach is helpful in dealing with multiethnic demands and interests that easily cause clashes and fractures. By rationally considering advantages and disadvantages of an issue, different ethnic groups may reach a solution through tolerance and respect. However, expecting every demand to be rational is too idealistic. Thus, during a dispute moderation is still the emphasis; advocating disagreement that is absent of yelling and screaming. Moderation would be the persuading tool to encourage groups of people to work out their disagreements and tame the possible radical elements within them.

Curiously the history of the Wasat party showed a different facet to an approach of moderation. Wickham (2004:207-212) argued that leaders and political parties moderated their agendas in order to exploit new opportunities for electoral participation created by democratisation. Based on the democratic process, leaders and political parties were willing to de-radicalise their stances, including efforts to reconstruct, renounce violence, and abandon the goal of revolution in post-transition elections, particularly in southern Europe and Latin America. Thus moderation becomes an integral party strategy for obtaining a parliamentary majority. Wickham (2004) further included another important example in Egypt, referring to the Wasat party founded in 1996 that embraced the wasatiyyah approach to its party. Wasat represented a form of political Islam that was different from extremist Islamic groups. It was a departure from Egypt's oldest and most influential Islamic political organisation in that it emphasised a reassessment of historical Syaria law coupled with ijtihad (the use of human reasoning to accommodate circumstances, with references to Al-Quran and Sunnah). As such it endorses pluralism, it supports equal rights to all citizens, and it affirms the popular vote for state sovereignty and power.

Such moderation is driven by not only a strategic calculation, but is also the result of politically learning to accommodate values and beliefs. It affords the party an institutional opportunity and incentive to integrate better interaction with voters as well as other Islamic political parties. In a most interesting condition the formation of the Wasat party occurred under increased repression and absence of democracy in Egypt. It was assumed that repression would trigger radicalization, but on the contrary, the Wasat party demonstrates an increased attempt to induce ideological moderation as a rational option. The Wasat party utilizes wasatiyyah approaches to seize new political opportunities and to evade new political constraints (Wickham, 2004: 213). However, well the Wasat party may moderate its party's motives, goals and agendas to enhance its credibility with the Egyptian electorate and co-operation with other secular opposition groups, these moderation efforts are weak (Note 3). The Wasat's moderation approach in politics, including its alliance with other secular opposition groups, was criticised as masking its true political intentions and thus the alliance did not last long. Furthermore, Wasat's version of a moderate political ideology was accused of promoting the western rationale and provoked a stricter Islamic rule; thus the party was viewed as betrayal to Islam (Wickham, 2004:214).

Although the Wasat party's application of moderation ended in misery, most power sharing models and elements embedded in them are still the main formulas for the integration of divergent political and organisational entities. The cost to promote peace and to maintain it offers tremendous benefits compared with the cost of war or chaos. Stimulating peace by using moderation in political coalitions, especially in a multiethnic country, has worked well to reduce unwarranted tension and to avoid any possible conflict. Nevertheless, the models for power sharing are appropriate for liberating the minds of self-interested parties or organisations whose victory for plural interests needs collective team work to achieve it. In fact, finding the common ground for power sharing could be a challenge, but reasons for it emerge from various causes and interests.

\section{Factors for Power Sharing: The Malaysian Experience}

Malaysia is a multi-racial society and it requires strong tolerance among races to achieve a delicate balance. Heterogeneity is difficult to achieve when each race has competing interests with which to deal. The power sharing model that applies in Malaysia particularly looking at the political parties is the grand coalition where several political parties representing each major ethnic group will form a pact or alliance. For instance, Barisan Nasional (Note 4) (BN) is composed of UMNO (United Malays National Organization), MCA (Malay Chinese 
Association), MIC (Malay Indian Congress), Gerakan, and other local parties in Sabah dan Sarawak including Parti Bersatu Sabah (PBS), Parti Bersatu Rakyat Sabah (PBRS), Sarawak United People's Party (SUPP), Parti Rakyat Sarawak(PRS), etc. While, Pakatan Rakyat (Note 5) is composed of Parti Keadilan Rakyat (People Justice Party), PAS (Pan Malaysian Islamic Party) and DAP (Democratic Action Party). The same power sharing formula is adopted by both political parties although the Barisan Nasional has applied this method since 1973 and successfully able to maintain its domination as the ruling party since independent of 1957 until present. Although the general election in 2008 and 2013 marked a significant shift of urban voters and the loss of 2/3 majority in the parliamentary seats to the opposition parties, BN rules still.

Even with inter and intra-race relationships, competing interests could disintegrate into factions that disrupt this delicate balance. The intra-racial factions within an ethnic group could spark conflict that turns into a complex condition where a portion of the ethnic group abandons its progeny and becomes aligned with another ethnic group. The Malays still maintain their beliefs and values despite differing political ideology between UMNO and PAS. Similar conditions exist with the Chinese between MCA and DAP. Although there is no moderation within these factions, the alliance among multi-ethnic political parties each representing an ethnic population is still relevant to understanding the quest for power sharing in Malaysia. Having competing interests with resource scarcity in a small country like Malaysia could be a blessing in disguise. Races need to depend on each another for resources, skills and capital.

While the rural Malays struggle with peasant-level economic limitations, urban Malays complain to petite bourgeois bureaucrats for more opportunities to enhance their capital incomes and standards of living. The Chinese populate most urban areas and now demand equality despite their economic good fortune. Some of the minority Indian populations still dwell in hardship on rural plantations while others of them manage to climb to higher income brackets and social positions. Proportionately the Malays are still the majority in public civil services, the Chinese control the private sectors, and the Indians make up the remaining positions in both public and private sectors. Here complementary interactions and relationships allow each race to stay calm and support each another. Reasons for harmonious coexistence include tolerance in the workplace, co-operation and peacekeeping within neighbourhoods and public schools, and the growing number of inter-ethnic marriages. All of these factors contribute to improving unity despite the diversity of sentiments they hold.

Perhaps this peace and unity may apply to circumstance where a race does not feel threatened or angry over an issue. There was an urban legend where either a motorist or car driver hit a person who lived in a village populated by another ethnic group and left the scene. If caught, the driver would be beaten to death. Many people believe this legend and they will be extra careful when driving or riding through densely populated villages belonging to ethnic groups other than their own. Despite the veracity of this urban legend, one thing that is certain is that Malay, Chinese, and Indian groups can be hostile within themselves when criminal cases such as domestic abuse, kidnapping, rape, or armed robbery are involved. On the other hand, these people from different ethnic background be placed in different circumstances, for instance the work environment, they are able to maintain interactions among races that reflect integrity, courtesy, and professionalism towards one another.

In fifty-six years of Malaysian independence, the only bitter incident reflecting poor race relations occurred in 1969. The tragedy was due to many factors including unequal economic distribution across ethnic groups (Jomo, 1986), poverty issues, and a disintegrated urban structure. The government took a strong role to restructure every issue related to race disintegration through several national programs including the New Economic Policy, the National Principles, Vision 2020, and the National Cultural Policy (Zahid, 1997; Ruslan et al., 2005). It is now evident that for a multiracial state to contend with varying interests, differences and diversity, the government must play a leading role in ensuring that the mission of unity is realised. Again and again the moderation approach to conflict resolution emerges as one of the best methods of maintaining harmonious relations among diverse ethnic groups.

Hanley (2008) discusses the meaning and mechanism of nation building, including the moderation approach, between Adam Smith and Rousseau. Both philosophers emphasise the limits of political intervention and the need to embrace a steady attachment to guide the universal principle of freedom. In other words, to leave the universal principle without a proper guidance will likely to degenerate into injustice. Thus, moderation requires an effort from legislators to navigate the ideal within context. Legislators must craft legislation that appeals to people's contexts because legislators have an imperfect understanding of the natural order that requires restraint and intervention. Thus, moderation is a way to embrace dealing with different issues every day. For instance, an act of terrorism may not be able to be resolved as moderately as a communal dispute over an educational system. The former requires an immediate action with zero tolerance especially when people's lives are at stake while the latter can be discussed and decided in a peaceful context, absent from hostility. 


\section{Beyond Power Sharing: Evidences}

According to Article 27 of the International Covenant on Civil and Political Rights as well as the United Nation Declaration on the Rights of Persons Belonging to National, Ethnic, Religious or Minorities, persons of minorities in multiethnic states shall not be denied the rights to enjoy their own culture, to profess and practice their own religion or to speak their language (Banton, 2010:30). The provisions for basic human rights and the freedom to practice and to profess is stipulated in the Malaysia Constitution, thus guaranteeing that in general such an atmosphere is present in Malaysia, underscoring its dedication to a multiethnic philosophy. The ethnic population diversity in Malaysia is approximately $65.1 \%$ Malays, $26 \%$ Chinese and $7.7 \%$ Indian from the total population of 23.7 million people (Department of Statistics, 2001). Indians may be considered as the minority, however each ethnic group enjoys its own cultural heritage, professes and practices its own religions and uses its own languages. Despite having a national language such as Malay, other languages are permissible in their usage at schools and in other public spheres.

Moreover it is better not to think of ethnic relations as a distinct class of social relations but rather as an ethnic dimension of social relations where people simply cross boundaries, settle into mixed marriages, convert and profess religions. Thus identification of a distinct ethnicity is now an expression of a preference. A person may not be able to identify himself with a clear ethnic lineage considering that the process of individual evolution into new family units involves other people of different ethnic backgrounds; in other words ethnic and identity are not static, but they are produced and reproduced over time (Rowley and Mhinder Bhopal, 2005:311). Changing preference is an individual's right and if doing so would further human tolerance, there is no harm in doing so. Viewing people as other than a distinct ethnicity would enhance their willingness to better understand each other. In fact, multiethnic societies help to diminish stigmas or stereotypes about an ethnic group and also help to foster case-by-case decisions rather than blanket judgements.

Traditionally pluralistic societies were commonly described as conflicted due to a number of belief systems, languages, cultures, interests and demands that could easily clash and turn catastrophic (Furnivall 1948). Cases such as Lina Joy (conversion from Muslim to Christian), the use of the word Allah in the Bible, Kampong Medan, Hindraf's demand, Dong Jiao Zong's educational demand, and some provocative incidents at a Hindu temple in Shah Alam, could have escalated into open conflicts or race riots. However each of these cases was resolved using the moderation approach through negotiation and proper legal procedure. Malaysia has a long tradition of practising a system of proper procedures and institutional channels so that issues can be resolved without the need to manipulate the situation. The enforcement agencies such as police and the Ministry of Home Affairs are alert and ready for fast action, not allowing any mischievous behaviour to escalate into a random race conflict.

Moreover in Malaysia after more than fifty years of independence, such potential conflict or chaotic description has become irrelevant. Furthermore such plurality and diversity of ethnic groups enriches Malaysia with colourful cultures, values and beliefs. Although they may look complex, they are integrating well into layers of societal structure. Cross-cultural celebrations are now embraced by every citizen. For example, the Chinese dragon dance with loud bands and fireworks is no longer intimidating. Similarly the Thaipusam ritual of the Hindus with sharp daggers inserted into the outer layers of skin on the body or face while carrying the kavadi is no longer a scary scene to all Malaysians. Both ceremonial events are popular, celebrated as public holidays for all workers and are becoming tourist attractions.

Along the same lines, a common critique that vernacular schools would further divide the society has given way to unity and a peaceful orientation in education. The vernacular schools were a demand of the Chinese and Indian cultures before independence, hoping that such orientations would help to cultivate and insure that future generations would be adhere to their believes, culture and values. Vernacular schools only exist at the primary and secondary level of education. Thanks to policies of tolerance, when children reach higher levels of education such as colleges and universities, all races are put together and they are able to communicate, integrate and pursue the future. The same situation is found in the work place, where an agency can be a place for many ethnic groups who work together in pursuing the agency's goal.

Even within the vernacular schools where the medium of interaction is another language such as Tamil, Bahasa Melayu or Malays language is taught as a compulsory subject to pass at the national examination levels. The application of Bahasa Melayu or the Malay language, at all schools allows all citizens to be able to communicate with one another across ethnic lines. In addition, the policy to promulgate the Malay language as the national language has been a very effective unifying agent in a plural society. The Malay language has been the lingua franca in the Malay Archipelago for thousands of years and in most countries in the world, the use of one 
language as a unifying agent has worked well. Now every single Malaysian can speak the Malay language, from an Iban grandmother in Sarawak to a Chinese grandmother in Perlis. They can communicate in the Malay language. Even better, some well-renowned professors in the Malaysian history and the Malay language are ethnically Chinese that speak very fluent Malay. (Note 6)

Another interesting phenomenon is the growing number of mixed marriages and families. Over the years in Malaysia they have helped to break down demographic profiling based on ethnic divisions. Additionally the assimilation process contributes to minimising group boundaries and inter-group social distances (Qian and Lichter, 2007). Dating back in Malaysian history, a Malay Sultanate, Sultan Mansur Shah (reigned 1456-1477) was married to a princess from China, Princess Hang Li Po; from their descendants the Chinese-Malay peranakan (Note 7) begun. Now they are well known as the Baba-Nyonya Melaka and at present mixed marriages with Malaysians are very common. Although there are a few hurdles encountered in mixed marriages such as divergent governmental procedures, issues of conversion, cultural subversion, and the dilemma of categorising multiracial children, these obstacles are not the reason for the failure of mixed married couples (Nidzam et al., 2012). Reasons for failure include unnecessary family intervention, adultery, irreconcilable differences on personal grounds, financial difficulty, and individual-family commitment issues (Kartini et al. 2012). These cases rarely escalate into abuse or racial conflict because they are treated or solved through the courts or other means of dispute resolution.

More demographic changes are seen in street foods or market places. All races are able to operate their food businesses on the same premises. Foods such as roti canai, nasi lemak, yong taufu, char koay teow, mee curry, and satay are among the local foods that are enjoyed by most Malaysians and these foods evolve with tastes contributed by each race. On every corner people of all races sit and eat together, whether at the same or different tables, just having conversation or watching soccer from the big screen television. There is no segregation; all are equal and enjoying each other's company. The feeling of national pride is evident during the soccer or badminton games, and supporting the Malaysian athletes regardless of race is a strong sentiment that these people share and cherish.

Therefore the demographic changes to the plural society in Malaysia are significant contributors to deconstructing the once-entrenched identification based on ethnicity, and of course a better mode for power sharing. Modern Malaysia is a more open society that is willing to offer a universal approach to human and societal services even though there will be a minority that is agitated at such progress. However such objections will become immaterial once the paradigm shifts due to continuous efforts from the government to cultivate and nurture the feeling of unity and belonging in the society. In fact, financial constraint and resource scarcity will be the main factors that could shift the paradigm from anti-establishment to supportive members of the state. This phenomenon is observable in most Non Governmental Organizations (NGOs) activities in Malaysia, and they are now the third force that helps maintain social cohesion between state and citizens.

Additionally, there are two obvious forms of NGOs; first interest groups that work on universal issues regardless of ethnicity such as the environmental groups including Sahabat Alam Malaysia (SAM), Consumer Association of Penang (CAP), and Malaysian Nature Society. Second, interest groups that are established to promote each different ethnic's interests, including Perkasa, Angkatan Belia Islam Malaysia, Dong Jiao Zong, Chinese Business Chamber, Hindraf, and The Malaysia Hindu Sangam. (Note 8) The demand for democratic participation through NGOs makes the growth of civil society significant in Malaysia. Despite groups' own interests that are ethnically distinct, a pressure from them could turn into racial issue. Thus the government has included NGOs in most of its agenda for development. The tactic seems to work effectively particularly when funding is made available for them. Consequently, such conditions limit NGOs mobility to mobilize its actual interest. NGOs are now binding themselves to fulfil the objectives set by the sponsor in order to ensure a continuous financial support for their survival.

\section{Conclusion}

Coalition, bargaining, negotiation and competition are embedded in Malaysia society. After fifty years of independence, Malaysia has significant experience in handling ethnic issues in a peaceful manner. Compared with other multi-ethnic societies such as Sri Lanka, Northern Ireland, Yugoslavia, and Africa, Malaysia has undoubtedly been more successful in maintaining order, harmony and development. The popular quotation from Furnivall (1948) that notes, "a plural society is rich with conflicts" is now obsolete because Malaysia has proven otherwise. As it has matured, the mutual understanding among ethnic groups has fully bloomed in this society. The prejudices, stigma and stereotyping have been significantly reduced. Kudos to the continuous efforts by the 
government, private and public sectors, society and citizens for ensuring that unity and harmony are maintained and preserved for posterity.

\section{References}

Baharudin, S. A. (2011). Culture and Governance in Malaysia Survival as a Nation. Ethnic Studies Paper Series, No. 2. KITA, UKM: Malaysia.

Banton, M. (2010). Ethnic Relations: An International Perspective on the Malaysian Initiative of 2007. Ethnic Studies Paper Series, No.9. KITA, UKM: Malaysia.

Bargsted, M. A., \& Kedar, O. (2009). Coalition Targeted Duvergerian Voting: How Expectations Affect Voters Choice under Proportional Representation. American Journal of Political Science, 53(2), 307-323. http://dx.doi.org/10.1111/j.1540-5907.2009.00372.x

Department of Statistics. (2001). Retrieved from http://www.statistics.gov.my

Diermeier, D., Swabb, R. I., Medvec, V. H., \& Kern, M. C. (2008). The Micro-Dynamics of Coalition Formation. Political Research Quarterly, 61(3), 484-501. http://dx.doi.org/10.1177/1065912908316981

Emby, Z. (1997). Rukun Negara (The National Principles) (Edited by A. K. A. Sabah, \& J. A. Jawan). UPM.

Eraslan, H., \& Merlo, A. (2002). Majority rule in a Stochastic Model of Bargaining. Journal of Economic Theory, 10, 31-48. http://dx.doi.org/10.1006/jeth.2001.2811

Fernando, J. M. (2012). Elite intercommunal bargaining and conflict resolution: The Role of the Communities Liasion Committee in Malaya, 1949-1951. Journal of Southeast Asian Studies, 43(2), 280-301. http://dx.doi.org/10.1017/S0022463412000069

George, A. L., \& Bennett, A. (2005). Case Studies and Theory Development in the Social Sciences. Cambridge, Massachusetts: Belfer Center for Science and International Affairs.

Hanley, R. P. (2008). Enlightened Nation Building: The Science of Legislators in Adam Smith and Rousseau. American Journal of Political Science, 52(2), 219-234. http://dx.doi.org/10.1111/j.1540-5907.2008.00309.x

Holyoke, T. T. (2009). Interest Group Competition and Coalition Formation. American Journal of Political Science, 53(2), 360-375. http://dx.doi.org/10.1111/j.1540-5907.2009.00375.x

Jomo, K. S. (1986). A Question of Class: Capital, the State and Development in Malaysia. Singapore: Oxford University Press.

Kessler, C. S. (2012). What Every Malaysia Needs to Know About Race. Ethnic Studies Paper Series. No. 19. KITA, UKM: Malaysia.

Lijphart, A. (1969). Consociational Democracy. World Politics, 21(2), 207-225. http://dx.doi.org/10.2307/2009820

Lijphart, A. (1977). Democracy in Plural Societies. New Haven, CT: Yale University Press.

Lijphart, A. (1991). Power Sharing Approach. In J. Montville (Ed.), Conflict and Peacemaking in Multi Ethnic Societies (pp. 491-510). New York: Lexington.

Mintzberg, H. (1983). Power and around organizations. Englewood Cliffs, New Jersey: Prentice Hall.

Qian, Z., \& Lichter, D. (2001). Measuring Marital Assimilation: Intermarriage among Natives and Immigrants. Social Science Research, 30, 289-312. http://dx.doi.org/10.1006/ssre.2000.0699

Rowley, C., \& Bhopal, M. (2005). The Role of Ethnicity in Employee Relations: The Cases of Malaysia. Asia Pacific Journal of Human Resources, 43(3), 308-331. http://dx.doi.org/10.1177/1038411105058704

Stevenson, W. B., Pierce, J. L., \& Porter, L. W. (1985). The Concept of Coalition in Organization Theory and Research. The Academy of Management Review, 10(2), 256-268.

Sulaiman, N., Talib, K. A., Hoon, P. G., \& Juan, R. L. (2012). Laporan Perkahwinan Campur dan Pembinaan Bangsa: Kajian Rintis. Institut Kajian Etnik, UKM: Malaysia.

Warwick, P. V. (2009). Relative Extremism and Relative moderation. Political Research Quarterly, 62(2), 276-288. http://dx.doi.org/10.1177/1065912908320663

Wickham, C. R. (2004). The Path to Moderation: Strategy and Learning in the Formation of Egypt's Wasat Party. Comparative Politics, 36(2), 205-228. http://dx.doi.org/10.2307/4150143

Zainuddin, R., Ismail, M. M., \& Othman, Z. (2005). Idealogi dan Dasar Negara. Kuala Lumpur. Oxford Fajar Sdn. Bhd. 


\section{Notes}

Note 1. Unity in diversity refers to several realms that ethicized in practice for instance, the economic realm from NEP (New Economic Policy) to NEM (New Economic Model). The nation economic plans are unable to detach economy from ethnicity. The rural Malays are unhappy and believe that they do not benefited from the policy, while the Chinese and Indians believe that the policy pro-Malays and discriminatory; the socio-cultural dispute on the vernacular schools, the endless debates and practice between eh Sharia and the civil law, the Malays privilege, and etc. Despite all these differences and difficulties, Malaysia has able to maintain peace and stability without worrying of any time bomb that could destroy the nation (Shamsul, 2011, p.37-40).

Note 2. Wasatiyyah comes from the Arabic word wasat which means moderate, not too soft and not too hard. It is at the middle, always balance and just. See Mahmood Zuhdi b Abdul Majid. 2013. Pendekatan Wasatiyyah dan Cabaran Ekstremisme di Malaysia, pg. 1-8. Seminar Pendekatan Wasatiyyah Memacu Peradaban Negara, 8 March 2013. Hotel InterContinental, Kuala Lumpur, Malaysia. Institute Wasatiyyah Malaysia (IWM).

Note 3. The Muslim brotherhood party won a series of stunning victory in Egyptian General Election from 1984-1993, See Wickham, 2004.

Note 4. http://barisannasional.org.my/parti-komponen, (accessed online 7 June 2013).

Note 5. http://www.pakatanrakyat.my/, (accessed online 7 June 2013).

Note 6. Prof Emeritus Dr Khoo Kay Kim (A Malaysia historian) of University Malaya, and Prof Dr Theo Kok Seong and Prof Dr Ding Choon Ming (the Malay language) Universiti Kebangsaan Malaysia are among non-Malays professors that are Malay proficient.

Note 7. Peranakan is the Malay word refers to a person's descendent that is not totally local neither alien. Peranakan is a result of a mixed marriage through the process of assimilation and amalgamation for generations, See Pue Giok Hun and Shamsul A.B. 2011. Discourse on Peranakanness with focus on the Peranakan Chinese Community in Contemporary Kelantan, Malaysia. International Proceedings of Economics Development and Research Vol. 20: Humanities, Society and Culture, Singapore: IACSIT Press, pg.241-245.

Note 8. See Jabatan Pendaftaran Pertubuhan, Kementerian Dalam Negeri, http://www.ros.gov.my/semakan_pertubuhan.php (accessed online 18 August 2010).

\section{Copyrights}

Copyright for this article is retained by the author(s), with first publication rights granted to the journal.

This is an open-access article distributed under the terms and conditions of the Creative Commons Attribution license (http://creativecommons.org/licenses/by/3.0/). 